Monetary policy and central bank behaviour

Manfred Gärtner

September 2002 Discussion Paper no. 2002-24 
Editor:

Publisher:

Electronic Publication:
Prof. Jörg Baumberger

University of St. G allen

Department of Economics

Bodanstr. 1

CH-9000 St. Gallen

Phone +41712242241

Fax +41712242885

Email_joerg.baumberger@ unisg.ch

Forschungsgemeinschaft für $\mathrm{N}$ ationalökonomie an der U niversität St. Gallen

Dufourstrasse 48

$\mathrm{CH}-9000$ St. Gallen

Phone +41712242300

Fax $\quad+41712242646$

www.fgn.unisg.ch/public/public.htm 


\title{
Monetary policy and central bank behaviour ${ }^{1}$
}

\author{
Manfred G ärtner
}

Author's address:

\author{
Prof. Manfred Gärtner \\ Department of Economics \\ Bodanstrasse 1 \\ $\mathrm{CH}-9000$ St. Gallen \\ Tel. $\quad$ +41712242307 \\ Fax +41712242874 \\ Email manfred.gaertner@ unisg.ch \\ W ebsite http://www.fgn.unisg.ch/gaertner/index.html
}

\footnotetext{
${ }^{1}$ Paper prepared for the Encyclopaedia of Public Choice, by Charles Rowley and Friedrich Schneider (eds.), Boston, Kluwer A cademic Publishers, forthcoming.
} 


\section{Abstract}

This paper surveys the state of the art on monetary policy and central bank behaviour from a public choice perspective. After a brief look at the roots of today's view of monetary policy conduct and institutional design in early work on political business cycles, the inflationstabilisation dilemma is discussed along with proposed solutions in the form of central bank independence and conservativeness, incentive contracts, and inflation targets. The final section turns to current developments, including the proper choice of policy targets, the role of $\mathrm{N}$ ew Keynesian aggregate-supply curves and the quest for monetary policy rules triggered by the Taylor rule.

\section{Keywords}

Monetary policy, Central banking, Public choice

\section{JEL Classification}

E31, E32, E52, E58 


\section{Introduction}

There are few areas in which public choice has had as much success in making inroads into mainstream economics and, in particular, in influencing real-life developments as in the design of monetary institutions and the day-to-day conduct of monetary policy. This survey tracks these developments, from the humble beginnings in the 1970s related to Nordhaus“ (1975) account of the opportunistic political business cycle to the widespread academic and political discussion on monetary policy rules and targets of today. ${ }^{1}$ Section 2 contains a compact review of the two classical ideas in political macroeconomics, the political business cycle and the inflation bias. Section 3 moves on to more modern, stochastic models, in which the desire for undistorted stabilization of supply shocks calls for refined remedies to the timeinconsistency problem, such as performance contracts and inflation targets for central banks. Section 4 moves on to a discussion of current developments which focus on instrument and targeting rules for monetary policy. Finally, section 5 briefly assesses these developments.

\section{How it started: political business cycles and all that}

Today‘s academic discussion and recent developments in monetary policy and institutions rest on three main pillars: The traditional theory of economic policy in the spirit of Theil (19xx) and Tinbergen (19xx); the endogenisation of economic policy, the groundwork for which was laid in many classical writings in public choice, but which main influence stems from the compact and compelling formalisations by Nordhaus (1975) and MacRae (1977); and, the rules-versus-discretion debate that came in the wake of the rational expectations revolution, with implications for endogenous policy making that were initially formalized by Kydland and Prescott (1977) but worked out and popularized by Barro and Gordon (1983). We will focus here on the public-choice-related roots of modern monetary policy conduct and design.

${ }^{1}$ This survey puts particular emphasis on recent, policy-related developments. Older developments are selectively discussed in order to bring out the public-choice roots of many current developments and provide a theoretical background for current discussions. For more detail on these earlier developments, readers may consult two previous surveys of mine which focus on political business cycles and the first-generation discussion of time-inconsistency (Gärtner, 1994) and the second-generation discussion of time-inconsistency including a refined macroeconomic framework with persistence and the interaction with fiscal policy (Gärtner, 2000). 
The birth of New Political Macroeconomics, as it would be called decades later, and, hence, also of positive analyses of monetary policy, was Nordhaus' concise formal demonstration of what opportunistic governments might do to an economy. In strong contrast to Theil-Tinbergen-type benevolent policymakers, opportunism takes the form of vote maximization at periodically held elections. Voters derive instantaneous or period utility from the state of the economy, as represented by inflation $\pi$ and the logarithm of income $y$ (or, alternatively, unemployment):

$$
u=-0.5 \pi^{2}+\xi y
$$

Votes cast on election day then reflect total utility and, hence, the course of the economy during the incumbent governments recent term in office, with more distant periods receiving less weight due to voter forgetfulness.

Operating within a natural-rate aggregate-supply framework in which income (or, again, unemployment) depend on inflation surprises, ${ }^{2}$

$$
y=\pi-E_{-1} \pi
$$

and inflation expectations are adaptive, governments maximize reelection prospects by resorting to expansionary policies, fiscal or monetary, in the run-up to an election, while deliberately driving the economy into a recession once the election is over, thus creating election-related swings in economic activity known as the political business cycle.

From the perspective of mainstream macroeconomics, the Nordhaus model (and its cousin, the partisan theory proposed by Hibbs (1977), which suggested that election-related swings were due to ideologically motivated s between the preferences of party constituencies) was almost dead on arrival. Despite the extraordinary interest it drew from public choice scholars, its key building blocks were at that time being discarded by macroeconomists: a nonvertical long-run Phillips curve (which was not essential to the political business cycle,

${ }^{2}$ We do not make a distinction between a Phillips curve and an aggregate supply curve. So simplify notation, we usually normalize the log of potential income, $y^{*}$, to zero and give the aggregate supply curve unity slope. 
however), adaptive inflation expectations, and backward-looking voters. A number of authors ${ }^{3}$ quickly pointed out that little in terms of added rationality in inflation expectations formation was required in order to eliminate the political business cycle.

While efforts by Alesina (1987), Persson and Tabellini (1990) and others gave the study of election-related macroeconomic cycles a vigorous second life under the labels of Rational partisan theory and Rational political business cycles, political business cycles do not feature prominently on today's research agenda any longer. ${ }^{4}$

Instead, research interest has shifted towards the rational-expectations equilibrium implications of endogenous policy making, with a particular emphasis on monetary policy. The starting point for this work, overlooked by most early critics, is the insight that while rational inflation expectations do indeed eliminate the political business cycle, they do leave the economy and policy trapped in a suboptimal, inefficient equilibrium. If monetary policy is driven by preferences such as (1), either because it caters to the electorate, or because this describes the government's or the central bank's very own preferences, the model's discretionary rational-expectations solution in the context of a one-shot game between the government and the economy is

$$
\pi=\xi
$$

Thus, despite the desire for full price stability inherent in (1), discretionary monetary policy cannot deliver. ${ }^{5}$ The reason is the time-inconsistency of price stability. Once it is achieved achieved with income being at its potential level, the central bank can always raise its own utility, or public support, by generating some inflation and a lot of income gains. While this mechanism and insight had already been described by Kydland and Prescott (1977), it attracted little attention until it was restated and popularized by Barro and Gordon (1983). The latter work triggered a still ongoing discussion of what institutional arrangements

${ }^{3}$ See, for example, Frey and Ramser (1976) and McCallum (1977).

${ }^{4}$ This, by any means, should not be read to mean that political business cycles are dead. See for example the contribution by Drazen (2000b).

${ }^{5}$ The inferiority of this result obtained under discretion is usually demonstrated by comparing it with the optimal inflation rate $\pi=0$ that obtains when the central bank has to commit to an inflation rate before expectations are being formed. 
would lead to the best macroeconomic outcomes, in particular, a reduction of the inflation bias. Initially, Barro and Gordon (1983) had suggested that reputational forces may take care of the inflation bias. However because such forces are strongly weakened when the government 's horizon does not extend to infinity, Rogoff's (1985) suggestion to put monetary policy into the hands of a conservative central bank, characterized by total oblevity towards income developments, received the most attention. In the above context, an arch conservative monetary policy guided by preferences $\hat{\xi}=0$ delivers full price stability without any detrimental effects on income. To achieve such policy, the governing body of the central bank must have preferences $\hat{\xi}=0$, and the central bank needs to be made completely independent of the government (which political competition forces to attend to the preferences of voters represented by $\xi){ }^{6}$ Condoned by the apparent empirical support for this proposition in the form of significant negative correlations between long-run inflation and measures of central bank independence ${ }^{7}$, the long ruling orthodoxy was that central banks must be completely independent and as conservative (meaning inflation averse) as possible. ${ }^{8}$

\section{Enter the stabilization bias}

Two innovations rekindled interest in the basic Nordhaus scenario and kept the discussion alive and vigorous up to the present:

The first was a modification of the utility function that gave inflation and income symmetric treatment. Nordhaus (1975), Kydland and Prescott (1977), Barro and Gordon (1983), and virtually hundreds of papers since, had employed an asymmetric functional form, assuming that utility depended nonlinearly on inflation, but linearly on income (or unemployment). This did help simplify the math, yet still sufficed to derive the political business cycle under adaptive inflation expectations and the inflation bias when expectations were rational.

The second innovation was to conduct the analysis in a more realistic stochastic context in which the economy was subject to supply shocks, and the potential need for

${ }^{6}$ See Eijffinger and Hoeberichts (1998).

${ }^{7}$ See Alesina and Summers (1993).

${ }^{8}$ See, however, Forder's (1998a, 1998b) illuminating and sobering account of the validity of empirical evidence on central bank independence and inflation. 
stabilization entered the picture.

\subsection{The trade between price stability and shock stabilization}

In order to demonstrate the implications of these two innovations, let us proceed from a hybrid utility function that comprises both the original asymmetric treatment (for $\alpha=0$ ) and the later symmetric treatment (for $\alpha=1$ ):

$$
u=-0.5 \pi^{2}-\alpha \xi(y-k)^{2}+(1-\alpha) \xi y
$$

$k>0$ is society's income target which is assumed to exceed potential income (which has been normalized to zero) because the latter is inefficiently low (also carrying involuntary unemployment) due to distortive taxes, monopolistic trade unions, legal constraints, and other imperfections in goods and labour markets.

Aggregate supply is subject to surprise inflation plus supply shocks $\varepsilon$ that are white noise with zero mean and variance $\sigma_{\varepsilon}^{2}$ :

$$
y=\pi-E_{-1} \pi+\varepsilon
$$

Maximizing equation (3) subject to (4) yields the following rational-expectations solutions for inflation and income:

$$
\begin{aligned}
& \pi=(1-\alpha) \xi+\alpha \xi k-\frac{\alpha \xi}{1+\alpha \xi} \varepsilon \\
& y=\frac{1}{1+\alpha \xi} \varepsilon
\end{aligned}
$$

Equations (5) and (6) convey three important insights:

1. The first two terms on the right-hand side of (5) constitute the inflation bias that monetary policy cannot get rid of, even in the absence of shocks. If utility is linear in $y(\alpha=$ 0 ) this bias equals $\xi$. If utility is nonlinear in $y$, with decreasing marginal utility $(\alpha=1)$, this bias amounts to $\xi k$. It is positive if $k$ exceeds potential income. Then the marginal utility of income is positive at the no-surprise equilibrium level, and inflation must be positive in order to generate a marginal disutility of inflation large enough to counterbalance the net temptation 
to raise income. At full price this does not apply because the marginal disutility of inflation is zero.

2. The coefficients in the stochastic terms of both (5) and (6) indicate how supply shocks are split into inflation and income responses. Note that the absolute values of the two coefficients sum up to one. ${ }^{9}$ So only $1 /(1+\alpha \xi)$ percent of any given adverse supply shock are actually permitted to drive income down, while the remaining $\alpha \xi /(1+\alpha \xi)$ percent materialize in increased inflation.

3. When utility is linear in $y(\alpha=0)$ the solutions simplify to $\pi=\xi$ and $y=\varepsilon$. Inflation is always constant at a level reflecting the conservativeness of monetary policy. Supply shock are never permitted to affect inflation, independently of the conservativeness of monetary policy.

The third insight states the specific conditions under which the famous monetarypolicy conservativeness result holds: In order to achieve second-best outcomes, that is, full price stability and the exact extent of shock stabilization society requests, monetary policy needs to be as conservative as possible in the sense that it should only look at the goal of price stability while ignoring movements of income altogether. ${ }^{10}$

If, however, more realistically, the utility function is symmetric $(\alpha=1)$, a dilemma pops up. To see this, note that the solutions for inflation and income now become

$$
\begin{aligned}
& \pi=\xi k-\frac{\xi}{1+\xi} \varepsilon \\
& y=\frac{1}{1+\xi} \varepsilon
\end{aligned}
$$

The key insight here is that in a stochastic context with decreasing marginal utility from income gains, delegating monetary discretion to an arch conservative central bank (characterized by $\hat{\xi}=0$ ) constitutes a fourth-best solution only. All it ensures is that we achieve price stability. The price to be paid are distorted responses to supply shocks. The

${ }^{9}$ This is because the aggregate supply curve has been give a slope of one. In the general case, the slope coefficient would also feature in the stabilization terms.

${ }^{10}$ For a result to be classified as first best, income also would have to be as required. Since this is considered to be beyond the reach of monetary policy, optimal monetary policy is only judged by whether it achieves second-best results. 
variance of inflation is minimized at $\operatorname{var}(\pi)=0 \cdot \sigma_{\varepsilon}^{2}=0$, but this goes at the cost of maximum variance of income at $\operatorname{var}(y)=\sigma_{\varepsilon}^{2}$. Society would prefer an intermediate solution, namely $\operatorname{var}(\pi)=[\xi /(1+\xi)]^{2} \sigma_{\varepsilon}^{2}$ and $\operatorname{var}(y)=[1 /(1+\xi)]^{2} \sigma_{\varepsilon}^{2}$. In the face of this trade-off between inflation bias and stabilization bias, a superior outcome, a third-best result, is achieved if society picks a more moderately conservative central bank, one that is more conservative than society, but not arch conservative ( $\xi>\hat{\xi}>0)$ [Rogoff (1985)].

Figure 1 may help clarify the trade-offs involved and serve as a background for issues addressed later on. The convex line constitutes the trade-off between income variability and inflation variability implied by the model. Society's preferences, represented by concave indifference curves, determine the desired split between income and inflation variability. We can move down along this line from the point on the ordinate (which obtains for $\hat{\xi}=0$ ) towards the point on the abscissa (which obtains for $\hat{\xi} \rightarrow \infty$ ). The dilemma is that in order to remove the inflation bias we need $\hat{\xi}=0$. This would put us into point $\mathrm{A}$ on the variance trade-off line with the variance of income being at a maximum at $\sigma_{\varepsilon}^{2}$ and the variance of inflation being at a minimum at zero. Society would prefer B. As we move from A towards B by raising $\hat{\xi}$, we reduce the stabilization bias, but pay by increasing the inflation bias. All we can achieve is a third-best optimum in a point such as $\mathrm{C}$, where society's net marginal benefit from increasing $\hat{\xi}$ is zero.

\section{[ Figure 1 near here ]}

The 1990s brought an avalanche of research on how to move beyond the third-best outcome generated by a moderately conservative central bank. This quest for second-best outcomes in a stochastic macroeconomic framework focussed on two main suggestions: To equip central bank chiefs with a performance contract, or to commit them to an inflation target. $^{11}$

${ }^{11}$ The discussion on performance contracts was initiated by Persson and Tabellini (1993), Waller (1995) and Walsh (1995). Major contributors to the early academic discussion of inflation targets in the current context were Herrendorf and Lockwood (1997), Muscatelli (1995) and Svensson (1997a). See also Bernanke and Mishkin (1997), and Walsh (1998), chapter 8 . 


\subsection{Performance contracts}

Equipped with a linear performance contract of the form $s=-\lambda \pi$, where $s$ is a variable component of the central bank's governing body's salary that depends on inflation, the central bank's derived utility function changes into

$$
u=-0.5 \pi^{2}-0.5 \hat{\xi}(y-k)^{2}-\lambda \pi
$$

Now optimal policy under discretion leads to the following behaviour of inflation and income:

$$
\begin{aligned}
& \pi=\hat{\xi} k-\lambda-\frac{\hat{\xi}}{1+\hat{\xi}} \varepsilon \\
& y=\frac{1}{1+\hat{\xi}} \varepsilon
\end{aligned}
$$

These results show that a properly designed linear performance contract can indeed lead to second best results. The inflation bias, comprising the first two terms on the right-hand side of (10), is removed if $\lambda=\hat{\xi} \pi$. And shock stabilization is prevented when the central bank's preferences are representative of society's ( $\hat{\xi}=\xi)$. This actually is ensured best if the central bank is not independent of the government. Whatever tendencies towards a higher inflation bias this may carry can easily be taken care of by setting the punishment coefficient in the performance contract appropriately. ${ }^{12}$

\subsection{Inflation targets}

Inflation targets have been very popular in academic research as a probably more realistic and viable alternative to performance contracts. Inflation targets also do provide a natural link from the literature discussed here to the recent intensive discussion of general monetary policy rules and targets at which we will look below. The general idea is that society (via the government) can communicate an inflation target $\pi^{T}$ to the central bank. The questions to be

${ }^{12}$ A linear contract focussing on the performance of aggregate income could be tailored to achieve the same second-best result, of course. The literature emphasizes inflation performance contracts, however. 
answered are, what this target should be, how target misses are to be punished, and what preferences the central bank should have.

After adding the inflation-target term to the central bank's utility function, the derived utility function reads

$$
u=-0.5 \pi^{2}-0.5 \hat{\xi}(y-k)^{2}-0.5 \lambda\left(\pi-\pi^{T}\right)^{2}
$$

Under discretion, the inflation rate follows

$$
\pi=\frac{1}{1+\lambda} \hat{\xi} k-\frac{\lambda}{1+\lambda} \pi^{T}-\frac{\hat{\xi}}{1+\lambda+\hat{\xi}} \varepsilon
$$

while income is determined by

$$
y=\frac{1+\lambda}{1+\lambda+\hat{\xi}} \varepsilon
$$

Again, a second-best optimum can be achieved. The condition for the inflation bias to disappear is $\pi^{T}=-\hat{\xi} k / \lambda$. This is an awkward result, however. No only because the central bank must be told to deflate, but even more so because the central bank systematically misses the assigned target. In the aspired zero-inflation equilibrium, the deviation from the inflation target must be large enough to offset any temptation to inflate that results from the central bank's own preferences. ${ }^{13}$

The condition for avoiding a stabilization bias is that the shock's coefficient in, say, (14), which describes the central bank's response, must be the same as the shock's coefficient in (8), which states society's desired response. This is accomplished if $\hat{\xi}=(1+\lambda) \xi$, meaning that now the government must pick a central banker who is less conservative, less inflationaverse than society.

Table 1 summarizes the consolidated knowledge about central bank independence and conservativeness in this section's macroeconomic environment. The important point it does

${ }^{13}$ Svensson (1997a) proposes that the central bank can simply be assigned a utility function which completely overrides any generic preferences which the central bank actually has. This formally solves the problem of a negative inflation target which is never met, but is arbitrary and unconvincing, not only from a public choice perspective. 
highlight is that little scientific support remains for the quest for the most independent, most conservative central bank that did and still does seem to shape the design and development of institutions in many of the world's countries and regions. ${ }^{14}$

\section{Table 1. How conservative should the central bank be?}

\begin{tabular}{ll}
\hline Macroeconomic and monetary policy framework & Optimal degree of central bank conservatism \\
$\begin{array}{l}\text { - Deterministic macroeconomic framework } \\
\text { - Baseline model (perfect discretion) }\end{array}$ & - arch conservative $(\hat{\xi}=0)$ \\
- Stochastic macroeconomic framework & \\
- Baseline model (perfect discretion), $3^{\text {rd }}$ best & - moderately conservative $(\xi>\hat{\xi}>0)$ \\
- Added performance contract; $2^{\text {nd }}$ best & - as conservative as society $(\hat{\xi}=\xi)$ \\
- Added inflation target; $2^{\text {nd }}$ best & - less conservative than society $(\hat{\xi}>\xi)$ \\
\hline
\end{tabular}

\subsection{A macroeconomic framework with income persistence}

The above findings do not change dramatically if, more in line with our empirical knowledge about the time series properties of income and other macroeconomic variables, we let shocks have lasting effects on income due to some degree of persistence, as in equation (15).

$$
y=\beta y_{-1}+\pi-E_{-1} \pi+\varepsilon
$$

Because inflation surprises and shocks now affect all future incomes, policy choices are being made so as to maximize the expected present value $E_{t-1} U_{t}$ of current and future period utilities:

$$
E_{t-1} U_{t}=\sum_{i=0}^{\infty} \delta^{i} E_{t-1} u_{t+i}
$$

Under discretion, there is still an inflation bias, which now takes the form

${ }^{14}$ The most prominent example is probably the European Central Bank, the blueprint for which does not seem to take account of the trade-offs and refined results emerging in a stochastic macroeconomic context. 


$$
\pi=\frac{\xi k}{1-(\alpha+b) \delta}-c y_{-1}-d \varepsilon
$$

$b, c$ and $d$ are coefficients composed of the structural equations parameters that we do not need to spell out here. ${ }^{15}$ This bias features a constant part which is similar to the bias in the natural rate framework discussed above. In addition to the familiar dependence on preferences $\xi$ this bias also depends on the degree of persistence $\beta$. The straightforward explanation is that the more persistent income is, the longer income gains generated by current inflation surprises last. But then the temptation to inflate is larger, and because this is anticipated by the labour market, we end up with a higher inflation bias.

The second term defining the inflation bias is endogenous, time-dependent. It states that this inflation bias is the higher, the lower income was last period. The mechanism at play here is that the marginal utility of income is higher when an adverse supply shock hit income last period and persistence will thus tend to keep income below potential income this period also. The central bank will thus be prepared to inject a larger inflation hike into the economy in the hope of income gains. But since again the labour market anticipates this, these income gains do not really accrue, and all we are left with is an inflation bias above average.

\subsubsection{State-dependent performance contracts}

While the math to demonstrate this is labourious, it is intuitively clear that a linear inflation performance contract cannot do away with this type of variable inflation bias. The required extension of the optimal contract is straightforward, though. Since the inflation bias is variable, dependent on last period's income, the performance contract must also be statedependent of the form

$$
s_{t}=-\left(\lambda_{1}-\lambda_{2} y_{t-1}\right) \pi_{t}
$$

This contract may specify $\lambda_{1}$ so as to eliminate the constant inflation bias, as in the natural-rate framework discussed above. And it may specify $\lambda_{2}$ such as to counterbalance the added incentive to inflate after income fell, thus removing the state-dependent inflation bias. Once the performance contract is designed optimally, central bank preferences should be

\footnotetext{
${ }^{15}$ For details, see Svensson (1997a).
} 
identical to society's in order not to bias stabilization. This mimics the result obtained in the natural-rate context.

\subsubsection{A state-dependent inflation target}

In the presence of income persistence inflation targets must be path dependent, comprising a constant term to take care of the fixed inflation bias and a term that follows lagged income

to take care of the variable inflation bias: $\pi_{t}^{T}=\beta_{0}+\beta_{1} y_{t-1}$. As Svensson (1997a) shows, however, even a state-dependent inflation target cannot get rid of both types of inflation bias, and keep stabilization undistorted. It must be combined with the appropriate central bank preferences that compensate for the stabilization bias introduces by the inflation target.

\section{Current developments}

Current research on monetary policy and central banks is looking for answers to three important questions:

1. How can the stabilization options be improved? Rather than discussing how different targets within a given family can be optimized so as to achieve second -best solution within a given trade-off, researchers turn to completely different target variables and how they may affect the trade-off options. We will exemplify this by comparing inflation targets as discussed above to price level targets.

2. Is the consolidated knowledge as surveyed in section 3 reasonably robust to changes in the macroeconomic environment within which monetary policy operates? A key role in this discussion is being played by the so-called New Keynesian aggregate supply curve which, in line with recent methodological changes in macroeconomics, is being derived from solid microfoundations and features forward-looking inflation expectations.

3. How can some of the more abstract theoretical insights of political macroeconomics be brought to bear on the actual conduct of monetary policy. This question is being discussed in a separate strand of research focussing on policy rules, which has close ties to the topics discussed so far.

\subsection{The choice of targets and their effects on trade-offs}

The question which macroeconomic variable monetary policy should target is not a trivial one. To demonstrate how that choice of target variables affects the variability of 
macroeconomic variables, as well as the implied trade offs between these variabilities, let us compare inflation targets with price level targets. In order to focus on the issue at hand, assume, as much of the literature does, that society can assign a target to the central bank in the strict sense that the target overrides any pertinent preferences the central bank itself may have (rather than adding it to the central bank's preferences, as assumed previously). Equipped with such an assigned inflation target, the central bank utility function reads

$$
u=-0.5\left(\pi-\pi^{T}\right)^{2}-0.5 \hat{\xi}(y-k)^{2}
$$

The discretionary optima for inflation and income that follow are

$$
\pi=\hat{\xi} k-\pi^{T}-\frac{\hat{\xi}}{1+\hat{\xi}} \varepsilon
$$

and

$$
y=\frac{1}{1+\hat{\xi}} \varepsilon
$$

The volatility trade-off from which society may choose by selecting $\hat{\xi}$ is characterized by $\operatorname{var}(\pi)=[\hat{\xi} /(1+\hat{\xi})]^{2} \sigma_{\varepsilon}^{2}$ and $\operatorname{var}(y)=[1 /(1+\hat{\xi})]^{2} \sigma_{\varepsilon}^{2}$, and depicted as the lower convex line in Figure 2. The specific target value $\pi^{T}$ neither affects the trade-off, nor where we end up on it. Actually, the depicted curve is an efficiency frontier. As long as monetary policy is governed by preferences coming from this very family of utility functions, comprising inflation and income as arguments that enter in quadratic form, we end up somewhere on this line. All society can do is move up or down this curve into its preferred point by picking $\hat{\xi}$.

Now other families of utility functions exist, comprising different variables or functional forms. An argument that is often advanced against in inflation targets for monetary policy is that it makes the variance of the price level go towards infinity as we increase the time horizon, making it difficult for individuals and firms to form expectations. In an attempt to remedy this, the government may assign a price level target to the central bank instead, even though society's preferences are still as given in equation (3) with $\alpha=0$. The central bank's utility function then reads 


$$
u=-0.5\left(p-p^{T}\right)^{2}-0.5 \hat{\xi}(y-k)^{2}
$$

where $p$ is the logarithm of the price level. Note that the aggregate-supply function (4) may be rewritten as

$$
y=p-E_{-1} p+\varepsilon
$$

since inflation is the first difference in the log of the price level. Maximizing (22) subject to (23) mimics the maximization of (19) subject to (4), except that the price level $p$ has taken the place of inflation $\pi$. Hence the solution for the price level is equal to the solution we previously derived for inflation,

$$
p=\hat{\xi} k-p^{T}-\frac{\hat{\xi}}{1+\hat{\xi}} \varepsilon
$$

Whether we assign an inflation target or a price level target has no effect on income which again follows

$$
y=\frac{1}{1+\hat{\xi}} \varepsilon
$$

Since $\pi \equiv p-p_{-1}$, the behaviour of inflation is directly derived from (24):

$$
\pi=-\frac{\hat{\xi}}{1+\hat{\xi}}\left(\varepsilon-\varepsilon_{-1}\right)
$$

This implies an inflation variance of $\operatorname{var}(\pi)=2[\hat{\xi} /(1+\hat{\xi})]^{2} \sigma_{\varepsilon}^{2}$, which is twice as large as when the central bank pursued an inflation target. As Figure 2 illustrates, this dramatically worsens the options for stabilization policy and is likely to affect society's pick of central bank conservativeness. In fact, a second-best optimum cannot even be achieved because $[\xi /(1+\xi)]^{2}=2[\hat{\xi} /(1+\hat{\xi})]^{2}$ - which would provide the right inflation variability - and $1 /(1+\xi)=[1 /(1+\hat{\xi})]-$ which would provide the desired variability of income - cannot be met at the same time. Independently of society's preferences, which we may not know, we can state that assigning a price-level target is inefficient. Switching to an inflation target permits lowering the variance of inflation (income) without raising the variance of income 
(inflation). ${ }^{16}$

[ Figure 2 near here ]

The example used here goes to show that the choice of a target variable, or variables, is a delicate one with obvious welfare implications. The inefficiency of price level targeting relative to inflation targeting is not robust, however, to changes in the macroeconomic framework. This is not really surprising, since the trade off is generated by the complete model, comprising both the macroeconomic structure and the incentives governing monetary policy. Svensson (1999b) demonstrates that, when faced with an economy with a sufficient degree of income persistence, society may be well advised to assign price-level targeting even though it possesses preferences cast in terms of an optimal inflation rate, because it results in lower inflation variability. Dittmar and Gavin (2000) show that in a model with a New Keynesian Phillips curve, as discussed in the following section, price-level targeting always generates a more favourable tradeoff between income and inflation variability, even if income is not persistent.

\subsection{The New Keynesian aggregate-supply or Phillips curve}

Roberts (1995) uses the Calvo (1983) model (in which prices are sticky because during any given period a firm has a fixed probability, strictly smaller than 1, that it may adjust prices) to show that a loglinear approximation about the steady state of the aggregated pricing decisions of individual firms reads

$$
y=\beta y_{-1}+\pi-E \pi_{+1}+\varepsilon
$$

While this aggregate supply curve looks very similar to the neoclassical supply curve with persistence that we used above, the inclusion of tomorrows expected rate of inflation rather

${ }^{16}$ Note that a price-level target here is only inefficient from the partial perspective of shock stabilization. Things are more complex when we bring the inflation bias into the picture, because, as we move down from the no-bias point on the ordinate, the bias increases as we move along the inflation-target trade-off, but not as we move along the price-leveltarget trade-off. 
than today's has important implications. ${ }^{17}$ One is that any movement in inflation, and particularly when it is rationally anticipated, affects income. ${ }^{18}$ Clarida, Gali and Gertler (1999) look at how this bears on the issues discussed in the preceding sections of this paper. Major findings are:

1. There is an inflation bias if the central bank has an income target that exceeds potential income. This is most easily rationalized if we think of monetary policy as a series of one-shot games in which policymakers take next period's expected inflation as given. It also holds in a more general setting, however, when the central bank has a longer horizon.

2. The inflation bias is negatively correlated with central bank conservativeness, that is, with the weight that the income target has in its utility function. An ,inflation nutter $(\hat{\xi}=0)$, as an arch conservative central bank is sometimes referred to, would entirely eliminate the inflation bias.

3. As a final analogue to results obtained within the Neoclassical framework, only a moderately conservative central bank would strike the right balance between the desires to reduce the inflation bias and to keep shock stabilization as undistorted as possible.

The framework used by Clarida, Gali and Gertler (1999), being somewhat richer than the one reported here, with shocks on the supply side and on the demand side, permits a host of other insights not directly comparable to the consolidated knowledge acquired within the neoclassical framework. A key issue that has been raised within this context, however, is whether preferences do indeed feature an income target which exceeds potential income, thus generating a problem of time inconsistency This is an important question, because if there was no inflation bias, or if it had different causes than presumed since spelled out by Kydland and Prescott (1977) and Barro and Gordon (1983), there might not exist the dilemma of choosing between inflation-bias reduction and less distortion of stabilization policy, making things much simpler for monetary policy.

As Cukierman (2002) has demonstrated, though, an income target exceeding normal

${ }^{17}$ For a detailed discussion of this and related New Keynesian aggregate supply curves and their implications for monetary policy see Clarida, Gali and Gertler (1999).

${ }^{18}$ Incidentally, a vote-maximizing government facing a backward-looking electorate and a New Keynesian aggregate supply curve with $\beta=0$ would create a political business cycle with some of the same features as the Nordhaus cycle. In fact, in a two period setting it would be the very same cycle that a government creates when aggregate supply is neoclassical and inflation expectations are of the simplest adaptive mould $\left(E_{-1} \pi=\pi_{-1}\right)$. 
or potential income is not necessary for an inflation bias to occur. All that is needed is an asymmetry in the central bank's utility function. Suppose preferences are such that the central bank wants income to rise, but only until it reaches potential income. It does not want push it beyond that level, but, if it exceeds potential income due to a favourable supply shock, it refrains from trying to drive it down. As a consequence, whenever a positive shock hits and income is above potential income, inflation remains at zero. Whenever a negative shock drives income below normal levels, monetary policy cushions that fall by creating inflation. As a result, average and expected inflation are strictly greater than zero. We have an inflation bias in equilibrium. In this context, much of the same remedies and policy recommendations would apply, with the math being a bit more cumbersome due to the employed piecewise utility functions.

\subsection{The quest for monetary policy rules}

This is probably the most active topic on today's research agenda on monetary policy. The field is still in a flux, and there are several perspectives from which to look at it. In order to understand the current discussion, we need to introduce some definitions. ${ }^{19}$

From a simplifying perspective there are two kinds of monetary policy rules. The first category comprises instrument rules. These specify how some instrument of monetary policy, typically an interest rate or monetary aggregate, responds to a set of macroeconomic variables. If these variables are predetermined at the time the instrument is being set, we speak of an explicit instrument rule. An implicit instrument rule specifies the instrument as a function of forward-looking variables that are not predetermined, of course. Due to this simultaneity between instrument and determining variables, this must be considered an equilibrium condition rather than a rule.

The second group of monetary policy rules comprises targeting rules. Characteristic for a targeting rule is the ,assignment" of a loss function to the central bank. If this loss function features only one target variable, say inflation, we have a strict targeting rule. If additional variables are included, say income, we speak of a flexible targeting rule. To the extent that the right or best target variables are difficult to control or to observe, the use of loss

19 We follow Svensson (1999), who is one of the most active contributors to this discussion. 
functions with intermediate targets is sometimes proposed. These targets should be highly correlated with the true goal, but easier to control and to observe.

Current research on monetary policy rules is related to the work reported in section 3 . But it also differs in a few major aspects:

1. There is a deliberate shift from a predominantly analytical towards a sophisticated yet practical monetary policy analysis, with strong doses of pragmatism and a quest for quantitative results. As consequence research interests of academics and central banks have begun to meet in this area. ${ }^{20}$

2. Employed models have been stripped of time inconsistency. So there is no more inflation bias and no more potential for conflict between price stability and stabilization policy. Stabilizing inflation and income around their desired values remains the only challenge. The discarding of the inflation bias appears to come as a response to criticism by a group of central bank notables and academics that the underlying story [Barro and Gordon (1983)] was unconvincing and empirically inaccurate. As a result, models are being employed in which a loss function or rule is imposed on the central bank that features an income target coinciding with potential income. ${ }^{21}$

3. While the New Classical or Lucas aggregate supply curve, more recently with added persistence, had completely dominated the literature discussed in section 3, there is no such consensus in the rules discussion. By contrast, this discussion accepts that no consensus regarding the right model of the macroeconomy has emerged yet, and emphasizes that this calls for thorough checks as to whether any derived rules are robust in the sense that they still function reasonably well within alternative macroeconomic models. These models cover a wide range of possibilities. Some reduce to a single equation. Some comprise up to a hundred equations. Some are derived from intertemporal optimizing behaviour of representative agents. Some are made up of equations purported to mimic the dynamic relationships we see

${ }^{20}$ There has been a host of conferences with „monetary policy rules“ in the title, sponsored or hosted by central banks. A first example is the conference jointly sponsored by the Sveriges Riksbank and the Institute for International Economic Studies at Stockholm University, held June 12-13, 1998, in Stockholm.

${ }^{21}$ Among those who have criticized the premise of central banks pursuing income targets which exceed potential income from the background of their hands-on experience with monetary policy making is Blinder (1995). Academic criticism of this idea has come, among others, from McCallum $(1995,1997)$ and Taylor (1983). 
in empirical VARs.

4. A final innovation characteristic of the rules discussion is the use of analytical and empirical methods that have become standard in real business cycle and dynamic general equilibrium analyses. This includes the calibration of models, stochastic simulations, and judgement of the empirical validity by means of comparing distributions of and correlations between simulated time series to those encountered in reality.

\subsubsection{The Taylor rule and other instrument rules}

Instrument rules for monetary and fiscal policy have a long tradition in economics. In the past, the most famous such rule was the Friedman rule, proposing that the money supply should grow at a fairly constant rate equal the trend growth rate of income. Such a rule is an explicit, if not an exogenous rule, since it hardly allows for any feedback from current economic variables into monetary policy, certainly not in the short run. ${ }^{22}$

Among the recent crop of more sophisticated monetary policy rules, which includes McCallum ‘s (1988) rule for the monetary base, the Henderson and McKibbin (1993) rule for the federal funds rate, and dozens of other rules, the rule that has swept the field is the one proposed by Taylor (1993). The Taylor rule states that the central bank has a real interest rate target, from which it deviates if inflation and/or income are off target. Solving this for the nominal interest rate yields

$$
i=r^{T}+\pi+0.5\left(\pi-\pi^{T}\right)+0.5(y-y *)
$$

When following the Taylor rule the central bank sets its instrument, the federal funds rate, at $r^{T}$ when inflation and income are at their optimal levels. An increase in inflation makes the central bank raise the nominal interest rate by a factor of 1.5. This raises the real interest rate, dampening effect aggregate demand. While it does not include any forward-looking variables, the Taylor rule can nevertheless call for preemptive strikes against future inflation. This is the case if rising income, which also drives up the real interest rate, drives up inflation with a lag.

\footnotetext{
${ }^{22}$ For an account of how the Friedman rule fared in practice, see Hafer and Wheelock
} (2001). 
Initially proposed as a descriptive and expository devise that can be used to account for the general flavour of monetary policy in the US and explain the Fed 's policy shift during the Volcker era, the Taylor rule has become much more. An an the meanwhile quite voluminous amount of empirical research suggests that Taylor's rule is indeed a quite reasonable description of policy behaviour of many central banks, including the Bundesbank, which is usually considered the most extreme ,inflation nutter ' in recent history. ${ }^{23}$ The rule also has come to fame in financial circles, where it is now a common tool for forecasting changes in the interest rate.

\subsubsection{Inflation targeting and other targeting rules}

As mentioned, a targeting rule is characterized by the assignment of a loss or utility function to the central bank. In section 3 we showed this in a parsimonious framework for inflation and income. Many possible targets are being discussed in the literature, such as the price-level, inflation, nominal GDP or nominal GDP growth, with inflation targeting drawing the most academic interest and being the most successful among central banks. ${ }^{24}$ The term inflation targeting is a misnomer, however, because only strict inflation targeting refers to a utility function of the form $u=-0.5\left(\pi-\pi^{T}\right)^{2}$. If additional target variables enter the utility function, this is being referred to as flexible inflation targeting. An example is the familiar utility function

$$
u=-0.5\left(\pi-\pi^{T}\right)^{2}-0.5 \xi(y-y *)^{2}
$$

which, for obvious reasons, might just as well be referred to as flexible income targeting.

In an effort to facilitate practical implementation or monitoring, a target rule is often expressed as a set of equations the target variables must fulfill. In the case of equation (29), if there is perfect control over the target variables and there is no trade-off, we obtain these

${ }^{23}$ See, for example, Clarida, Gali and Gertler (1998), who estimate policy reaction functions for the G3 (Germany, Japan, and the US) and the E3 (UK, France, and Italy) countries, and Peersman and Smets (1998), who explore the Taylor rule as a benchmark for analysing monetary policy in the euro area.

${ }^{24}$ It is generally believed that quite a number of central banks, including those of Australia, Canada, New Zealand, Sweden and the U.K. have adopted some form of inflation targeting during the last ten to fifteen years. 
equations from the first-order conditions for the unrestricted maximum of the utility function as $\pi=\pi^{T}$ and $y=y *$. If control is imperfect, the expected values must equal the targets. Things do become much more complicated, however, when, as is always the case, we have trade-offs between macroeconomic variables, be it within periods or intertemporarily. While first-order conditions usually still exist, they may be too complicated for practical purposes. It may then be advisable to switch to intermediate target variables which, ideally, should be „highly correlated with the goal, easier to control than the goal, easier to observe than the goal, and transparent" [Svensson (1999a), p. 619]. In terms of how to pursue the target, Svensson (1999a) further reports that the target variable included in the loss function is usually not the best indicator for the instrument to respond to.

\subsubsection{Comparing instrument and targeting rules}

From a purely technical viewpoint, instrument and targeting rules are simply two sides of the same coin. Maximization of any utility function or target subject to a macroeconomic model leads to an optimal instrument rule. For example, maximization of (29) with respect to the instrument $\pi$, subject to (4), gives the instrument rule $\pi=\pi^{T}-\varepsilon \xi /(1+\xi)$. This may be rewritten. After solving (4) for $\varepsilon$ and substituting the result, we obtain

$$
\pi=\pi^{T}-\xi\left(E_{-1} \pi-\pi^{T}\right)-\xi(y-y *)
$$

The result is a Taylor-like instrument rule in which the instrument $\pi$ depends on the income gap and on the expected deviation of inflation from the inflation target. We may note here that (28) is not an explicit instrument rule. The endogeneity of income on the right-hand side makes this rule implicit, an equilibrium condition. ${ }^{25}$

${ }^{25}$ The Taylor rule maximizes a utility function such as (29) only then as a strict instrument rule, if sufficient lags make inflation and income predetermined when the interest rate is being set. A pragmatic macroeconomic structure, purported to parsimoniously represent results from typical VARs that interest rates affect income after one year and inflation after two years, that serves this purpose comprises a dynamic $I S$ curve,

$$
y=-\beta r_{-1}+\gamma y_{-1}+\varepsilon
$$

and an accelerationist aggregate supply curve (without expectations),

$$
\pi=\pi_{-1}+\delta y_{-1}+\eta
$$

where all variables are measured as deviations from their targets. Minimization of the loss function $\operatorname{var}(\pi)+\xi \operatorname{var}(\mathrm{y})$, which directly relates to (29), yields an explicit interest rate rule: 
Just as the optimization of a given utility or loss function generates an explicit or implicit instrument rule, any given instrument rule can be trace back to a utility function that is being optimized. This mapping from preferences to instrument rule or back does, of course, crucially depend on the macroeconomic model to which it is attached, and it may not be unique.

The competition between instrument and target rules thus boils down to the question of which one is more practical. A starting point for this discussion must be that realistic models of the macroeconomy are much more complex than the models we looked at. While this need not affect the utility function to be assigned to the central bank, it leads to immensely complicated optimal instrument rules, which will also be very difficult to monitor. On the other hand, it will also bear heavily on how a central bank pursues its assigned targets. It is flexible in doing so, however, and free to incorporate any progress the science of economics may make. As our view of how the economy functions changes, the target(s) need not be adjusted. An instrument rule, by contrast, would have to be adjusted continuously, which may lead into credibility problems. But this is where the conceded uncertainty about the proper macroeconomic model comes into play. Robustness studies of instrument rules produced two interesting results: ${ }^{26}$

First, complex, optimal instrument rules derived from one specific model perform poorly when plugged into a different model. So using such a rule would be very risky if we have serious doubts about the true nature of macroeconomic transmission channels and interaction.

Second, simple instrument rules, taken from the same family as the Taylor rule, do not perform much worse than the complex optimal rule.

Third, and this is actually implied in the second result, the near-optimal performance of simple rules is rather robust across a wide spectrum of models.

Ball (1999) addresses the issue of preference uncertainty, referring to $\xi$, the relative weight of income stabilization in society's utility function. In terms of Figure 2 he proceeds

$$
r=\hat{\alpha} \pi+\hat{\beta} y
$$

where the coefficients depend on the model's structural coefficients. See Ball (1999).

${ }^{26}$ See the conference volume edited by Taylor (1999), which focusses on the issue of how robust various policy rules perform in a variety of different macroeconomic frameworks. 
from the assumption that we do not know society's indifference curves. Then the best we can do is focus on efficiency and identify those rules or targeting variables that generate lower trade-off lines, so that society can be made better off, now matter what the weight parameter is in its utility function. Employing a calibrated version of the macroeconomic model shown in footnote 25, Ball compared inflation targeting, nominal GDP growth targeting, and the Taylor rule. In this framework inflation targeting is efficient and nominal GDP growth targeting is inefficient. The verdict for the Taylor rule is mixed. In its original form reported as equation (28), i.e. endowed with the coefficients of 0.5 advocated by Taylor, the rule is inefficient. In order to make a rule with the same structure as the Taylor rule efficient, the interest rate response to output gaps would have to be about twice as high. This rule can be derived from the efficient inflation target.

\section{Assessment and outlook}

Monetary policy is an exciting field to work in these days, both for its intellectual and methodological challenges and for its close interaction with policy makers and institutions. From a public choice perspective, nevertheless, and despite the enormous progress that is being achieved, recent developments may cause mixed feelings. In a way one may wonder whether, on an undisputedly higher level of theoretical and methodological sophistication, we are not coming back full circle to fostering and refining the seemingly extinct art of optimal economic policy making as envisaged by Tinbergen and Theil. The resurgence of a more technocratic approach becomes obvious when we interpret recent developments against the political macroeconomics approach that was dominating the discussion until a few years ago and that we traced in the first half of this survey. It's main structure is sketched in Figure 3.

Figure 3 near here

The political- macroeconomics approach has three building blocks: the preferences of society (or voters), the preferences of the policymaker (here the central bank), and a macroeconomic model (usually degenerated into an aggregate supply equation). Monetary policy conducted within the stochastic macroeconomic model generates economic outcomes which are then evaluated by society on the basis of its preferences. The key result is that monetary policy governed by society's preferences produces an inefficient outcome featuring 
an undesired, high level of price instability. Society can improve on this suboptimal outcome in a number of ways. One way to achieve price stability without distorting the stabilization of shocks is to set new incentives for the central bank by picking a progressive central bank which cares a lot about income, making it independent of the government, and adding an inflation target to its environment.

The current applied discussion of rules and targets questions all three building blocks that characterize the public choice approach:

1. Society has no more desire for income to exceed potential income. So preferences are compatible with what can be achieved in the long run, both regarding price stability and the level of income. This eliminates the inflation bias, and, hence, the dilemma of a potential trade-off between an inflation and a stabilization bias. In fact, monetary policy governed by society's preferences generates an optimal long-run equilibrium and stabilization as desired.

2. The central bank has no preferences of its own. It can either be ,assigned“ a loss function (as for instance in the inflation targeting approach), or a reaction function.

3. Finally, and this is one of the strong points, current research about rules and targets accepts as a fact that economists do not agree on a correct macroeconomic model.

On the issue of whether there is a basis for time inconsistency and excessive inflation, it is hard to see why society should settle for potential income as its optimal choice. If potential income is indeed the result of a series of distortions, as is argued for most industrial countries, and comes along with such burdens as involuntary unemployment, shouldn't we want higher income. Do Europeans really not want their 10 percent a-priori risk of being unemployed to fall? This is, in effect what we are claiming when we argue that the desire for income not to exceed potential income is in our preferences. It is something entirely different if we decide that we do not want to draw one monetary policy to raise income. This would be the result of a cost-benefit calculation on the basis of the macroeconomic options, from which we might conclude that a short-lived income hike was not worth the price of a lasting increase in inflation. Our preferences are an element in this calculation, but must not be confused with the calculation itself. $^{27}$

Discarding the central bank's generic preferences and assuming it can simply be

${ }^{27}$ For further arguments on the pros and cons of an income target in excess of potential income, see Walsh (1998), p. 370f. 
assigned any utility function or instrument rule is similarly worrisome. This might be a plausible approximation when fines for deviations from the assigned instrument or targeting rules are so large that personal preferences are dwarfed. But this does not really seem to and cannot really be the idea in a world of change in which rules a best be a frame of reference for policy decisions. Non of these rules tells us how to adjust target levels in an evolving macroeconomic environment, how to implement a rule or switch from one to another, how to respond to financial bubbles or other phenomena outside our standard models.

So, measured against what political macroeconomics achieved and contributed to monetary policy making and designed, current developments may be seen as a setback. Devising optimal rules and targets is certainly useful, but so are plans of how to eat right. The problem is that even its proponents see and sell monetary policy rules as a general framework with plenty of discretion. But then, what are optimality and robustness studies that are based on the strict application of a particular rule worth, if we do not know under what circumstances, how often, and in what direction central banks will deviate from or even change the rule? Such questions obviously cannot be addressed without returning the preferences of society and the central bank back into the equation and, hence, reactivating the public-choice element in monetary policy research. 


\section{References}

Alesina, A. (1987). Macroeconomic policy in a two-party system as a repeated game. Quarterly Journal of Economics 102, 651-678.

Alesina, A. and L. Summers (1993).Central bank independence and macroeconomic performance. Journal of Money, Credit, and Banking 25, 157-162.

Ball, L. (1999). Efficient rules for monetary policy. International Finance 2, 63-83.

Barro, R. and, D. Gordon (1983). Rules, discretion, and reputation in a model of monetary policy. Journal of Monetary Economics 12, 101-121.

Bernanke, B.S. and F.S. Mishkin (1997). Inflation targeting: a new framework for monetary policy. Journal of Economic Perspectives 11, 97-116.

Blinder, A. (1995). Central banking in theory and practice: lecture II: credibility, discretion, and independence. Marshall Lecture, University of Cambridge, May.

Calvo, G. (1983). Staggered prices in a utility maximizing framework. Journal of Monetary Economics, 383-398.

Clarida, R., Gali, J., and M. Gertler (1998). Monetary policy rules in practice: Some international evidence. European Economic Review 42, 1033-1067.

Clarida, R., Gali, J., and M. Gertler (1999). The science of monetary policy: A New Keynesian perspective. Journal of Economic Literature 37, 1661-1707.

Dittmer, R. And W.T. Gavin (2000). What do New-Keynesian Phillips curves imply for pricelevel targeting? Federal Reserve Bank of St. Louis Review, March/April, 21-27.

Drazen, A. (2000a). Political economy in macroeconomics. Princeton University Press: Princeton.

Drazen, A. (2000b). The political business cycle after 25 years. NBER Macroeconomics Annual, May.

Eijffinger, S. and M. Hoeberichts (1998). The trade off between central bank independence and conservativeness. Oxford Economic Papers 50, 397-411.

Forder, J. (1998a). The case for an independent European central bank: A reassessment of evidence and sources. European Journal of Political Economy 14, 53-71.

Forder, J. (1998b). Central bank independence - conceptual clarifications and interim assessment. Oxford Economic Papers 50, 307-334.

Frey, B.S. and H.-J. Ramser (1976). The political business cycle: a comment. Review of Economic Studies 43, 553-555.

Gärtner, M. (1994). Democracy, elections and macroeconomic policy: two decades of progress. European Journal of Political Economy 10, 85-109.

Gärtner, M. (2000). Political macroeconomics: A survey of recent developments. Journal of Economic Surveys 14, 527-561.

Hafer, R.W. and D.C. Wheelock (2001). The rise and fall of a policy rule: monetarism at the St. Louis Fed, 1968-1986. Federal Reserve Bank of St. Louis Review, January/February, 1- 24.

Henderson, D.W. and W.J. Mc Kibbin (1993). An assessment of some basic monetary policy regimes pairs: analytical and simulation results from simple multi-region macreocnomic models. In: R.C. Bryant, P. Hooper and C.L. Mann (eds.), Evaluating policy regimes: new research in empirical macroeconomics. The Brookings Institution, Washington D.C., 45-218.

Herrendorf, B. and B. Lockwood (1997). Rogoff's conservative central banker restored. 
Journal of Money, Credit and Banking 29, 476-495.

Hibbs, D.A. (1977). Political parties and macroeconomic policy. American Political Science Review 71, 1467-1487.

Kydland, F.E. and E.J. Prescott (1977). Rules rather than discretion: the inconsistency of optimal plans. Journal of Political Economy 85, 473-491.

MacRae, D.C. (1977). A political model of the business cycle. Journal of Political Economy $85,239-263$.

McCallum, B.T. (1977). The political business cycle: an empirical test. Southern Economic Journal 43, 504-515.

McCallum, B.T. (1988). Robustness properties of a rule for monetary policy. CarnegieRochester Conference Series on Public Policy 29, 173-204.

McCallum, B.T. (1997). Critical issues concerning central bank independence. Journal of Monetary Economics 39, 99-112.

Muscatelli, A. (1995). Delegation versus optimal inflation contracts: do we really need conservative central bankers? University of Glasgow Discussion Paper no. 9511.

Nordhaus, W. D. (1975). The political business cycle. Review of Economic Studies 42, 169-190.

Peersman, G. and F. Smets (1998). Uncertainty and the Taylor rule in a simple model of the euro-area economy. Mimeo.

Persson, T. and G. Tabellini (1990). Macroeconomic policy, credibility and politics. Harwood Academic Publishers: Chur.

Roberts, J.M. (1995). New Keynesian economics and the Phillips curve. Journal of Money, Credit, and Banking 27, 974-984.

Rogoff, K. (1985b). The optimal degree of commitment to an intermediate monetary target. Quarterly Journal of Economics, November, 1169-1189.

Svensson, L.E.O. (1997). Optimal inflation targets, 'conservative' central banks, and linear inflation contracts. American Economic Review 87, 98-114.

Svensson, L.E.O. (1999a). Inflation targeting as a monetary policy rule. Journal of Monetary Economics 43, 607-654.

Svensson, L.E.O. (1999b). Price-level targeting versus inflation targeting: a free lunch? Journal of Money, Credit, and Banking 31, 276-295.

Taylor, J.B. (1983). Comments on ,Rules, discretion and reputation in a model of monetary policy' by R.J. Barro and D.B. Gordon. Journal of Monetary Economics 12, 123-125.

Taylor, J.B. (1993). Discretion versus policy rules in practice. Carnegie-Rochester Conterence Series on public Policy 39, 195-214.

Taylor, J.B. (1999), ed. Monetary Policy Rules. A National Bureau of Economic Research Conference Report. Chicago: University of Chicago Press.

Theil, H. (1961). Economic forecasts and policy, $2^{\text {nd }}$ ed. Volume XV of Contributions to Economic Analysis. Amsterdam: North-Holland.

Tinbergen, J. (1952). On the theory of economic policy, $2^{\text {nd }}$ ed. Volume I of Contributions to Economic Analysis. Amsterdam: North-Holland.

Wagner, H. (1999). Inflation targeting versus monetary targeting. Kredit und Kapital, 610632.

Waller, Ch. J. (1995). Performance contracts for central bankers. Federal Reserve Bank of St. Louis Review, September/October, 3-14.

Walsh, C.E. (1995). Optimal contracts for central bankers. American Economic Review 85, $150-167$.

Walsh, C.E. (1998). Monetary theory and policy. MIT Press: Cambridge, Mass. 
Monetary policy and central bank behavior, page 28

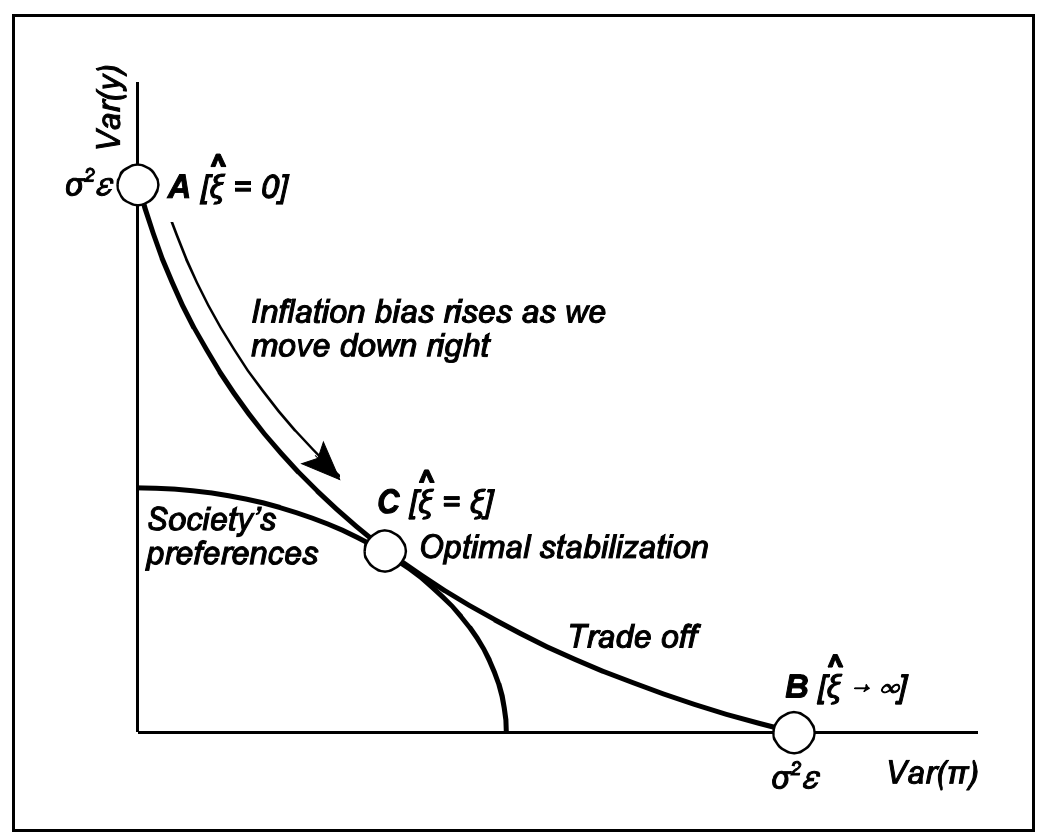

Figure 1 
Monetary policy and central bank behavior, page 29

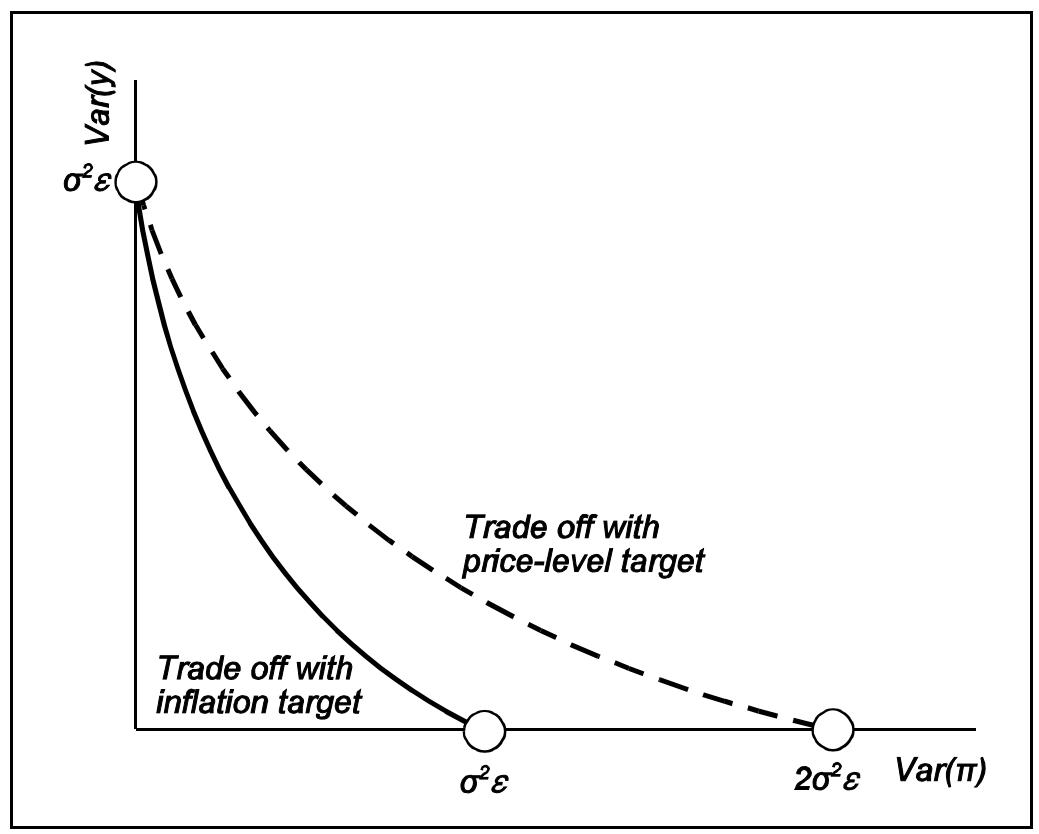

Figure 2 
Monetary policy and central bank behavior, page $\mathbf{3 0}$

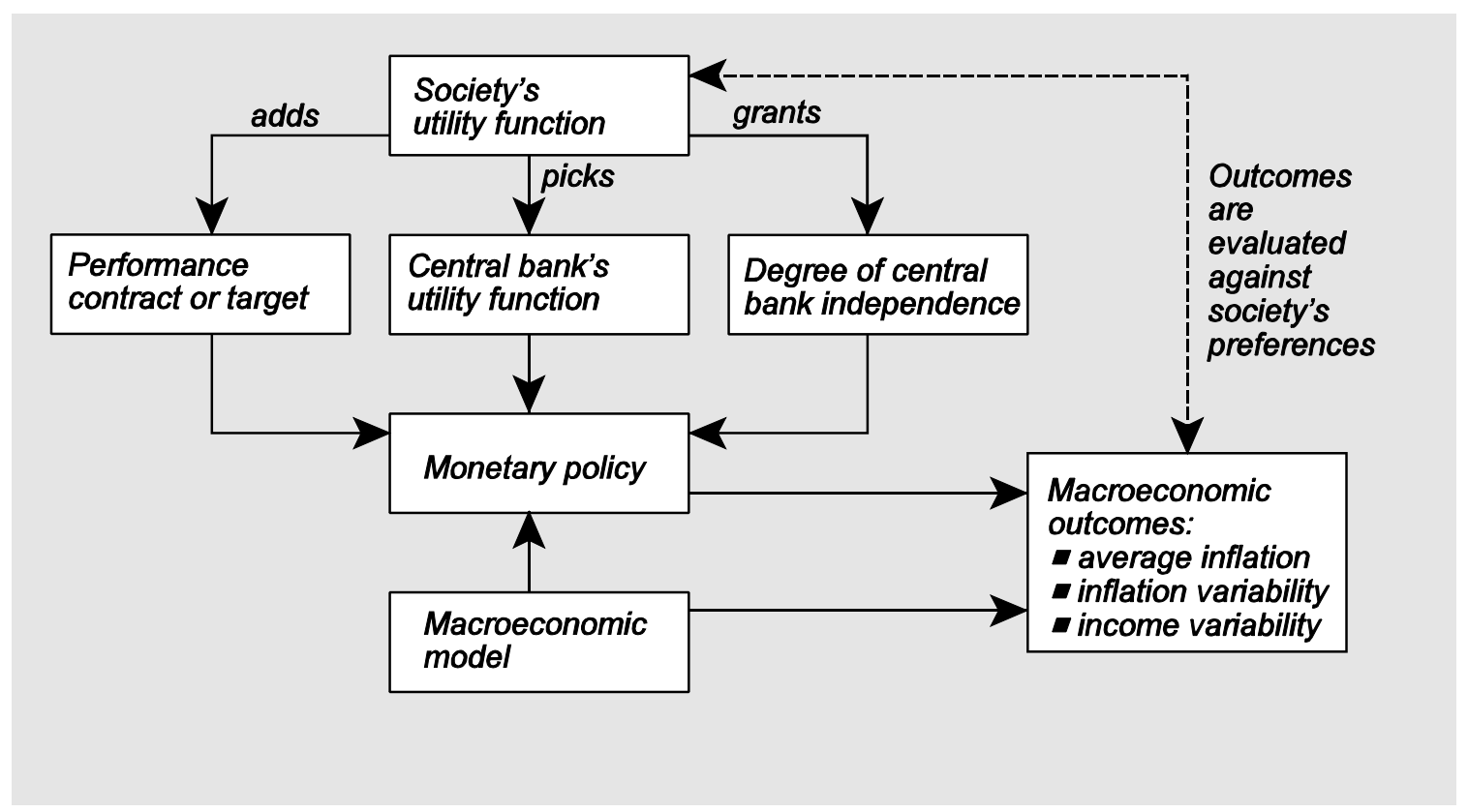

Figure 3 